\title{
In silico Evaluation of Selected Compounds from Bergenia ciliata (Haw.) Sternb against Molecular Targets of Breast Cancer
}

\author{
Sabiha Enam Spriha, S. M. Abdur Rahman* \\ Department of Clinical Pharmacy and Pharmacology, Faculty of Pharmacy, University of Dhaka, Dhaka, BANGLADESH.
}

\begin{abstract}
Background: A daunting public health issue that mainly affects women is breast cancer. Resistance to drugs applied in the treatment of this cancer as well as their side effects have made it necessary to look for new therapeutic agents. Objectives: The study is aimed at identification of multi-targeted inhibitors of molecular targets associated with breast cancer. Methods: We investigated fifteen compounds from Bergenia ciliata (haw.) Sternb against four major molecular targets of breast cancer viz; estrogen receptor- $\alpha$ $(E R-\alpha)$, progesterone receptor (PR), human epidermal growth factor receptor 2 (HER2/ ERBB2) and epidermal growth factor receptor (EGFR) by docking simulation. Properties describing $A D M E / T$ aspects of the potential compounds were also investigated by in silico approach. Results: Among the fifteen compounds investigated, stigmasterol, $\beta$-sitosterol, paashaanolactone and afzelechin exhibited more or comparable binding affinity values with the different targets compared to that of native ligands and therefore may be developed as leads for multi-targeted therapy against breast cancer. Conclusion: Considering the molecular docking results and ADME/T analysis, it can be suggested that these compounds can be subjected to further structural modification and in vivo analysis for evaluating the potential of their candidacy as new drugs in the field of treatment and management of breast cancer.
\end{abstract}

Key words: Bergenia ciliata, Breast cancer, In silico, Molecular docking, ADME.

\section{INTRODUCTION}

Breast cancer with approximately 1.5 million worldwide diagnosis each year is the second responsible reason for death in women among different types of cancers. ${ }^{1}$ It has been estimated that the incidence of breast cancer in women will be about 3.2 million anually by the year $2050 .^{2}$ Diagnosis and mortality rate are much higher in postmenopausal women than in premenopausal women. In 2018, 1.4 million postmenopausal and 645000 premenopausal women were diagnosed with breast cancer globally. ${ }^{3}$ Incidence is highest in women from high and high-middle income countries whereas mortality rates are higher in women from low -middle and low income countries. ${ }^{4}$ Increased incidence in higher income countries may be due to lifestyle factors and lower mortality can be attributed to better treatment facilities. ${ }^{5}$ Metastasis of breast cancer is associated with $90 \%$ of the observed mortality. ${ }^{6}$ The survival of patients with metastatic breast cancer ranges from 8.0 to 36.0 months. $^{7}$ Risks factors associated with breast cancer can be both modifiable and non-modifiable. Family history, benign breast cancer disease, high mammographic density, age and sex are among the non-modifiable factors. ${ }^{8}$ The major modifiable risk factors involve weight, alcohol consumption, hormone replacement therapy and hormonal contraceptives. ${ }^{9}$ Breast cancer is often classified into subgroups by varied level of expression of estrogen receptor (ER), progesterone receptor (PR) and human
Submission Date: 26-05-2021; Revision Date: 09-08-2021; Accepted Date: 25-11-2021

DOI: 10.5530/ijper.56.1s.49 Correspondence: Dr. SM Abdur Rahman Dean, Faculty of Pharmacy, Professor and Chairman, Department of Clinical Pharmacy and Pharmacology, University of Dhaka, Dhaka-1000, BANGLADESH.

Email-smarahman@du.ac. bd

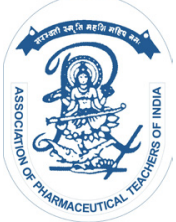

www.ijper.org 
epidermal growth factor receptor 2 (HER2/ ERBB2) in cancer cells. Luminal A subtype is marked by abnormal cells that are ER and PR positive but negative for HER2. ${ }^{10}$ ER + tumor with higher expression of HER2 is classified as luminal B (HER2+) and with normal level expression of HER2 is classified as luminal B (HER2-). ${ }^{11}$ Basal like breast cancer/triple negative breast cancer is indicated by absence of expression of ER, PR and also HER2 with poor prognosis. ${ }^{12}$ Current major treatment options for breast cancer comprise surgical intervention, radiotherapy, chemotherapy, hormonal therapy and targeted therapy depending on type, stage, menopausal status and many other factors. ${ }^{13}$ Patients diagnosed with luminal A type are treated primarily with oral endocrine therapy such as ER modulator and aromatase inhibitors. ${ }^{14}$ Tamoxifen which is a selective ER modulator exerts its antiestrogen effect by competitively inhibiting binding of estrogen to ER whereas letrozole, anastrazole and other aromatase inhibitors reduce the production of estrogen. ${ }^{15}$ AntiHER2 therapy with trastuzumab, pertuzumab, lapatinib and others alone or in combination are extremely useful in treating HER2+ cancer. ${ }^{16}$ Systemic treatment regimen for basal like breast cancer is not specific and different molecular targets such as epidermal growth factor receptor (EGFR), poly ADP-ribose polymerase (PARP), androgen receptor (AR) and various pathways are being investigated. ${ }^{17}$ In spite of unprecedented development in breast cancer treatment strategies, the problem of resistance to therapeutic agents used in all subtypes is still to be solved and more therapeutic options need to be searched for luminal B and aggressive triple negative type breast cancers. ${ }^{18}$

Plants are used as a source of medicine from ancient to present time. They have proven to be a great source of anticancer drugs. ${ }^{19}$ Vinca alkaloids, taxols, podophyllotoxins, camptothecin along with their semisynthetic or synthetic derivatives are notable anticancer agents from plant origin. The plant in our current study, Bergenia ciliata (haw.) Sternb of Saxifragaceae family is a perennial herb that grows mainly in different temperate and cold parts of East and Southeast Asia. ${ }^{20}$ It contains numerous classes of compounds including phenols, sterols, flavonoids, glycosides, terpenoids and saponins. ${ }^{21}$ The most commonly used part of this herb is its rhizomes followed by leaves. ${ }^{22}$ Rhizome of Bergenia ciliata contains bergenin -a glycoside as main constituent and rhizomes are also found to contain a novel lactone called paashanolactone. ${ }^{23}$ Aerial part of this plant also contains bergenin along with other glycosides and flavonoids. ${ }^{24}$ Antiurolithic, anticancer, antimicrobial, antioxidant, antidiabetic and anti-tussive effects have been investigated for this plant. ${ }^{25-28}$ Silver nanoparticles prepared from aqueous extract of Bergenia ciliata rhizomes have shown anticancer potential via inhibition of protein kinase activity. ${ }^{29}$ Brine shrimp bioassay using rhizome extract showed pronounced cytotoxic activity at low doses. ${ }^{30}$ Both methanolic and aqueous extracts of Bergenia ciliata exhibited potent concentration dependent cytotoxicity on MDA-MB$435 \mathrm{~S}$ cell line which is a human breast carcinoma cell line. ${ }^{31}$ However, there is no extensive data and in silico study of its compounds of this plant against breast cancer. Therefore, in the present study, we investigated some selected compounds from Bergenia ciliata against four molecular targets related to breast cancer i.e. ER- $\alpha$ (estrogen receptor- $\alpha$ ), PR (progesterone receptor), HER2 (human epidermal growth factor receptor 2) and EGFR (epidermal growth factor receptor) to get preliminary idea about breast cancer protective effect of this multipotent plant.

\section{MATERIALS AND METHODS}

\section{Molecular docking simulation}

Three dimensional crystal structures of major molecular targets of breast cancer i.e. ER- $\alpha$ (PDB code: 3ERT, R-value free: 0.262 , resolution: $1.90 \AA)^{32}$ PR (PDB code: 4OAR, R-value free: 0.234, resolution: $2.41 \AA$ ) , ${ }^{33}$ HER2 (PDB code: 3RCD, R-value free: 0.294, resolution: $3.21 \AA$ ), ${ }^{34}$ and EGFR (PDB code: 2J6M, resolution: $3.10 \AA$, R-value free: 0.249$)^{35}$ were acquired from Research Collaboratory for Structural Bioinformatics Protein Data Bank (https://www.rcsb. org/). Complexed ligands and water molecules were eliminated and hydrogens were added to the structures. A total of fifteen compounds from Bergenia ciliata illustrated in Figure 1 were docked against the proteins. Molecular structures of the compounds were obtained from the PubChem database. Energy minimization of the compounds were performed applying mmff 94 force field in Open Babel (version 2.4.0). ${ }^{36}$ Molecular docking simulation was carried out in AutoDock Vina (version 1.1.2). ${ }^{37}$ Docking procedure was validated by re-docking the native ligands in the binding pockets of corresponding proteins. Active sites of ER- $\alpha$, PR, HER2 and EGFR were selected analyzing binding interaction of tamoxifen, ulipristal acetate, TAK-285 and AEE788, respectively. Grids used for docking were placed on the active sites of the proteins. The grid co-ordinates $(\mathrm{X}, \mathrm{Y}, \mathrm{Z})$ for docking against ER- $\alpha, \mathrm{PR}, \mathrm{HER} 2$ and EGFR were $(26.48,-1.06,26.92),(11.85,27.09$, 14.34), (14.56, -2.26, 25.13) and $(-51.70,-0.54,-19.26)$, respectively. The dimension of grids were 25.00, 25.00, 
25.00 angstrom. Interaction of the compounds with the targets were analyzed with Discovery Studio Client 2019.

\section{In silico ADME/T prediction}

Molecular properties i.e. molecular weight, hydrogen bond donors and acceptors, lipophilicity, molar refractivity as described in Lipinski's rule of five were determined using SwissADME. ${ }^{38}$ The ADME and toxicological attributes of the compounds were predicted from online server admetSAR (http://lmmd. ecust.edu.cn/admetsar2/.

\section{RESULTS AND DISCUSSION}

\section{Molecular docking simulation}

Molecular docking of fifteen compounds from Bergenia ciliata were performed against four major molecular targets of breast cancer viz; ER- $\alpha$, PR, HER2 and EGFR. Binding affinities of each compound and corresponding native ligands with the target proteins are shown in Table 1. Among the fifteen compounds investigated, stigmasterol, $\beta$-sitosterol, paashaanolactone and afzelechin were found to have higher binding affinities

\begin{tabular}{|c|c|c|c|c|}
\hline \multicolumn{5}{|c|}{$\begin{array}{c}\text { Table 1: Binding affinities of compounds from } \\
\text { Bergenia ciliata and native ligands towards } \\
\text { molecular targets of breast cancer. }\end{array}$} \\
\hline Compounds & ER- $\alpha$ & PR & HER2 & EGFR \\
\hline Native ligands & -9.7 & -9.2 & -10.7 & -8.5 \\
\hline Afzelechin & -8.8 & -8.3 & -8.3 & -8.2 \\
\hline Methyl nonanoate & -5.2 & -5.3 & -4.8 & -4.4 \\
\hline B-asarone & -5.9 & -6.1 & -5.9 & -5.3 \\
\hline Bergenin & -6.5 & -6.5 & -6.5 & -7.3 \\
\hline Methyl cinnamate & -6.2 & -6.3 & -5.8 & -5.4 \\
\hline Damascenone & -6.6 & -7.0 & -6.7 & -6.2 \\
\hline Gallicin & -8.4 & -7.7 & -7.2 & -7.6 \\
\hline Isobutyrophenone & -6.2 & -6.5 & -6.1 & -5.5 \\
\hline Isovaleric acid & -4.5 & -4.6 & -4.5 & -4.0 \\
\hline Limonene & -5.9 & -6.6 & -5.8 & -5.3 \\
\hline Parasorbic acid & -5.2 & -5.2 & -5.2 & -4.3 \\
\hline Paashaanolactone & -8.7 & -8.9 & -8.7 & -8.0 \\
\hline$\beta$-sitosterol & -8.7 & -8.4 & -9.2 & -8.3 \\
\hline Stigmasterol & -9.4 & -9.4 & -10 & -8.8 \\
\hline Terpinen-4-ol & -6 & -6.6 & -5.5 & -5.6 \\
\hline
\end{tabular}

Native ligands for ER- $\alpha$, PR, HER2 and EGFR are tamoxifen (PubChem CID: 2733526), ulipristal acetate (PubChem CID: 130904), TAK-285 (PubChem CID: 11620908) and AEE788 (PubChem CID: 10297043) respectively. Binding affinities are expressed in $\mathrm{kcal} / \mathrm{mol}$. towards ER- $\alpha$, PR, HER2 and EGFR than other compounds. The binding pattern of these compounds with the proteins are shown in Table 2 and Table 3. Stigmasterol exhibited greater binding affinity of -9.4 and $-8.8 \mathrm{kcal} / \mathrm{mol}$ towards PR and EGFR, respectively, when compared to -9.2 and $-8.5 \mathrm{kcal} / \mathrm{mol}$ of respective native ligands. Although $\beta$-sitosterol, paashaanolactone and afzelechin did not exhibit higher binding affinity than native ligands of the proteins but their binding affinities are considerable.

ER- $\alpha$ is expressed over normal levels in $50 \%$ of all breast cancers and it is implicated in both the commencement and progression of the cancer. ${ }^{39}$ Tamoxifen is the most widely applied anti-estrogen therapy but it poses increased risk of uterine cancer, pulmonary embolism and stroke. ${ }^{40}$ Therefore, bioactive compounds from nature can be a great source for anti-estrogen therapy. $\beta$-sitosterol and stigmasterol have shown potential activity against ER- $\alpha$ in several in silico and in vitro studies. ${ }^{41}$ In this study, both the phytosterols have also exhibited noticeable binding affinity and interacted with the ligand binding domain of ER- $\alpha$. $\beta$-sitosterol interacted with the receptor through hydrophobic and Van der Waals interaction without forming any hydrogen bonding with the amino acid residues of the active site. This interaction of $\beta$-sitosterol is similar to that of tamoxifen which also interacts with ER- $\alpha$ with only hydrophobic and Van der Waals interaction and unlike the agonist estradiol that interacts through hydrogen bonding with Arg394A and His524A residues. ${ }^{42}$ Stigmasterol had greater binding affinity towards ER- $\alpha$ than $\beta$-sitosterol with a binding affinity of $-9.4 \mathrm{kcal} / \mathrm{mol}$ which is comparable to $-9.7 \mathrm{kcal} / \mathrm{mol}$ of tamoxifen. It also exhibited only hydrophobic and Van der Waals interaction with the receptor active site. Afzelechin which is a tetrahydroxy flavan, formed hydrogen bonding with Gly521A residue and showed hydrophobic interaction with Leu346A, Ala350A, Leu387A, Leu391A, Met421A and Leu525A residues. It possesses chemical structure similar to that of kaempferol which is reported to have the ability to modulate ER- $\alpha$ expression. ${ }^{43}$ Therefore, further in vitro study can be accomplished to get idea about its pharmacological action. Paashaanolactone formed hydrogen bonds with Leu346A and Thr347A residues of ER- $\alpha$ within its active site with considerable binding affinity. It also interacted with hydrophobic amino acid residues Leu346A and Leu525A. The binding patterns of afzelechin and paashaanolactone are illustrated in Figure 2.

PR can modify the behavior of ER- $\alpha$ and its expression is used as biomarker for breast cancer. ${ }^{44}$ Investigation 
Table 2: Binding interactions of compounds from Bergenia ciliata with amino acid residues of ER- $\alpha$ and PR.

\begin{tabular}{|c|c|c|c|c|}
\hline Protein & Compounds & $\begin{array}{l}\text { Hydrogen bond } \\
\text { (distance in } \AA \text { ) }\end{array}$ & Hydrophobic interactions & Van Der Waals interactions \\
\hline \multirow{4}{*}{ ER- $\alpha$} & Afzelechin & Gly521 (3.67, 3.91) & $\begin{array}{c}\text { Leu346, Ala350, Leu387, Leu391, } \\
\text { Met421, Leu525 }\end{array}$ & $\begin{array}{c}\text { Met343, Leu349, Glu353, Leu384, } \\
\text { Met388, Arg394, Phe404, Glu419, } \\
\text { Gly420, Ile424, His524 }\end{array}$ \\
\hline & $\beta$-sitosterol & - & $\begin{array}{l}\text { Met343, Leu346, Leu349, Ala350, } \\
\text { Trp383, Leu384, Leu387, Met388, } \\
\text { Leu391, Leu525 }\end{array}$ & $\begin{array}{c}\text { Thr347, Asp351, Arg394, Phe404, } \\
\text { Ile424, Met528 }\end{array}$ \\
\hline & Paashaanolactone & $\begin{array}{c}\text { Leu346 (4.60), Thr347 } \\
\text { (3.93) }\end{array}$ & Leu346, Leu525 & $\begin{array}{l}\text { Met343, Leu349, Ala350, Asp351, } \\
\text { Glu353, Trp383, Leu384, Leu387, } \\
\text { Met388, Leu391, Arg394, Phe404, } \\
\text { Met 528 }\end{array}$ \\
\hline & Stigmasterol & - & $\begin{array}{l}\text { Leu346, Ala350, Leu354,Trp383, } \\
\text { Leu384, Leu387, Leu525, Leu536 } \\
\text { Leu539 }\end{array}$ & $\begin{array}{c}\text { Met343, Thr347, Asp351, Met388, } \\
\text { Leu391, Phe404, Met421, Leu428, } \\
\text { Met528 }\end{array}$ \\
\hline \multirow{4}{*}{ PR } & Afzelechin & Ile699 (3.63) & $\begin{array}{c}\text { Pro696, Val698, Val729, Trp732, } \\
\text { Leu758 }\end{array}$ & $\begin{array}{c}\text { Leu721, GIn725, Ser728, Gly762, } \\
\text { Phe778, Ala779, Pro780, }\end{array}$ \\
\hline & $\beta$-sitosterol & - & $\begin{array}{l}\text { Leu718, Leu721, Trp755, Met759, } \\
\text { Val760, Leu763, Phe778, Met801, } \\
\text { Cys891, Leu2350B }\end{array}$ & $\begin{array}{c}\text { Asn719, Gly722, Glu723, Gln725, } \\
\text { Arg766, Met756 }\end{array}$ \\
\hline & Paashaanolactone & $\begin{array}{c}\text { GIn725 (3.52), Leu758 } \\
(5.83), \text { Arg766 (4.24, } \\
5.14,5.63) \text { Lys822 (4.24) }\end{array}$ & Ile699, Pro696, Leu721, Ala779 & $\begin{array}{l}\text { Glu695, Asp697, Val698, Ser728, } \\
\text { Val729, Trp732, Met759, Gly762, } \\
\text { Leu763, Trp765, Phe778, Phe818 }\end{array}$ \\
\hline & Stigmasterol & - & $\begin{array}{l}\text { Leu715, Leu718, Phe778, Trp755, } \\
\text { Met759, Phe794, Leu797, Met801, } \\
\text { Ile896, Cys891 }\end{array}$ & $\begin{array}{l}\text { Asn719, Gly722, Glu723, Leu726, } \\
\text { Met756, Tyr890, Leu892, Asn893, } \\
\text { Gln897, Thr894, Leu2350B }\end{array}$ \\
\hline
\end{tabular}

\begin{tabular}{|c|c|c|c|c|}
\hline Protein & Ligands & $\begin{array}{l}\text { Hydrogen bond (distance } \\
\text { in } A \text { ) }\end{array}$ & Hydrophobic interactions & Van Der Waals interactions \\
\hline \multirow{4}{*}{ HER2 } & Afzelechin & $\begin{array}{c}\text { Ala751 (4.07), Lys753 (4.81), } \\
\text { Thr862 (3.37) }\end{array}$ & Leu726, Val734, Leu852 & $\begin{array}{c}\text { Ile752, Leu785, Val797, Thr798, } \\
\text { Gly804, Cys805, Asp863, } \\
\text { Phe1004 }\end{array}$ \\
\hline & $\beta$-sitosterol & - & $\begin{array}{c}\text { Phe731, Val734, Ala751, Lys753, } \\
\text { Leu755, Leu785, Leu796, } \\
\text { Leu852 }\end{array}$ & $\begin{array}{l}\text { Leu726, Met774, Thr798, } \\
\text { Cys805,Thr862, Asp863, Gly865 }\end{array}$ \\
\hline & Paashaanolactone & $\begin{array}{c}\text { Asn850 (4.08), Thr862 } \\
\text { (5.02), Asp863 (3.84), } \\
\text { Ser783 (4.90) }\end{array}$ & $\begin{array}{l}\text { Val734, Ala751, Leu785, Leu852, } \\
\text { Phe864 }\end{array}$ & $\begin{array}{l}\text { Lys753, Leu796, Thr798, } \\
\text { Cys805 }\end{array}$ \\
\hline & Stigmasterol & Thr862 (4.47), Asp863 (4.08) & $\begin{array}{c}\text { Leu726, Val734, Ala751, Lys753, } \\
\text { Leu800, Cys805, Leu852 } \\
\text { Phe1004 }\end{array}$ & $\begin{array}{l}\text { Gly727, Ser783, Leu785, } \\
\text { Leu796 Thr798, Met801, } \\
\text { Gly804, Asp808 }\end{array}$ \\
\hline \multirow{4}{*}{ EGFR } & Afzelechin & - & $\begin{array}{c}\text { Leu718, Val726, Ala743, Lys745, } \\
\text { Thr790, Leu844 }\end{array}$ & $\begin{array}{l}\text { Gly719, Glu762, Met766, } \\
\text { Leu777, Leu788, GIn791, } \\
\text { Leu792, Met793, Pro794, } \\
\text { Gly796, Thr854, Asp855 }\end{array}$ \\
\hline & $\beta$-sitosterol & - & $\begin{array}{l}\text { Leu718, Val726, Ala743, Lys745, } \\
\text { Met766, Leu788, Leu844 }\end{array}$ & $\begin{array}{c}\text { Gly719, lle744, Glu762, Thr790, } \\
\text { Leu792, Met793, Pro794, } \\
\text { Gly796, Cys797, Thr854 }\end{array}$ \\
\hline & Paashaanolactone & $\begin{array}{l}\text { Lys745 (4.55), Met793 } \\
\text { (4.02), Pro794 (5.21) }\end{array}$ & Val726, Met766, Leu788 & $\begin{array}{l}\text { Leu718, Phe723, Ala743, } \\
\text { Glu762, Thr790, Gln791, } \\
\text { Leu792, Phe795, Gly796, } \\
\text { Leu844, Thr854, Asp855 }\end{array}$ \\
\hline & Stigmasterol & Glu762 (6.71) & $\begin{array}{c}\text { Leu718, Val726, Ala743, Lys745, } \\
\text { Leu792, Met793, Cys797, } \\
\text { Leu844 }\end{array}$ & $\begin{array}{c}\text { Gly719, Phe723, Met766, } \\
\text { Thr790, Pro794, Gly796, } \\
\text { Thr854, Asp855 }\end{array}$ \\
\hline
\end{tabular}



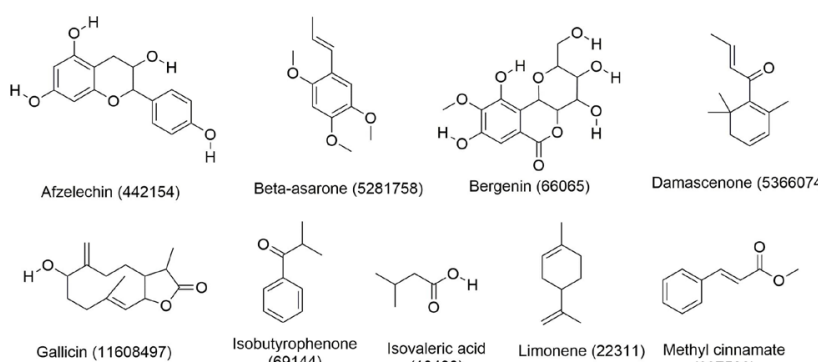

Beta-asarone (5281758)

Bergenin (66065)
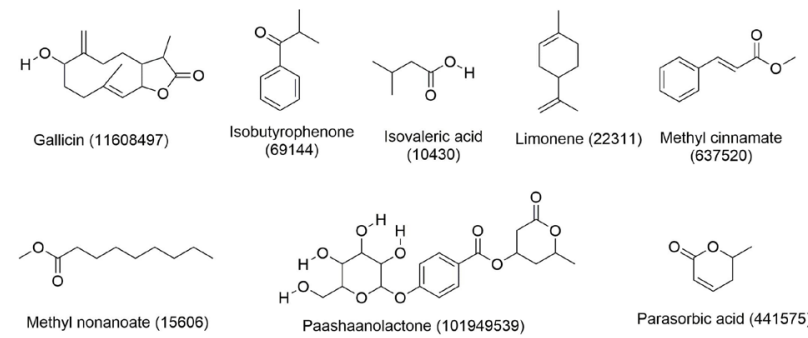

Methyl nonanoate (15606)

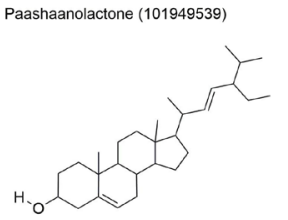

Stigmasterol (5280794)
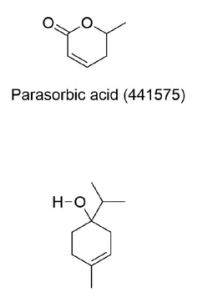

Terpinen-4-ol (11230)
Beta-sitosterol (222284)

Figure 1: Chemical structure of the compounds from Bergenia ciliata with their PubChem ID number that were selected for in silico analysis.

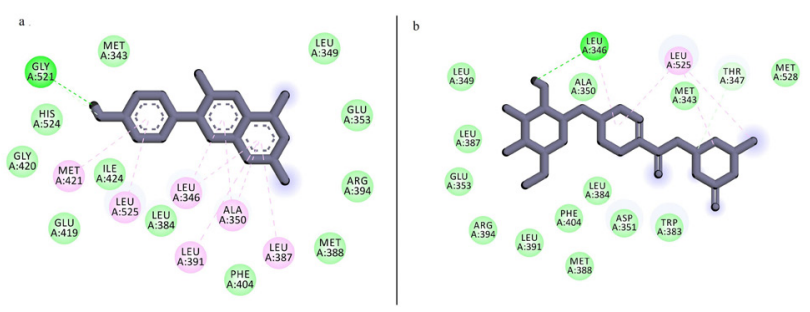

Figure 2: Interaction of (a) afzelechin and (b) paashaanolactone with estrogen receptor- $\alpha(E R-\alpha)$. Green (with dashed line): hydrogen bond; pink (with dashed line): hydrophobic; light shaded green: Van der Waals; cyan (with dashed line): carbon- hydrogen interaction.

of synthetic and natural progesterone antagonists is rising as data from different in vitro and animal model studies have shown optimistic results. ${ }^{45}$ Stigmasterol exhibited binding affinity of $-9.4 \mathrm{kcal} / \mathrm{mol}$ which is higher than $-9.2 \mathrm{kcal} / \mathrm{mol}$ of reference ligand ulipristal acetate towards PR. It showed hydrophobic interaction with Leu715A, Leu718A, Phe778A, Trp755A, Met759A, Phe794A, Leu797A, Met801A, Ile896A and Cys891A residue of PR. Paashaanolactone also had comparable binding affinity to that of ulipristal acetate exhibiting five hydrogen bond interaction with three residues of PR i.e. Gly725A, Leu758A and Arg766A. It is noteworthy that apigenin which is a reported PR modulator flavonoid also forms hydrogen bond with Gly725A and Arg766A residues. ${ }^{46}$ The binding patterns of stigmasterol and paashaanolactone are illustrated in Figure 3.
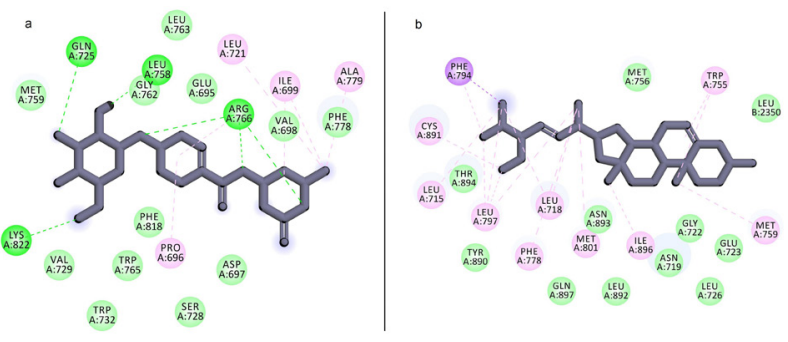

Figure 3: Interaction of (a) paashaanolactone and (b) stigmasterol with progesterone receptor (PR). Green (with dashed line): hydrogen bond; pink (with dashed line): hydrophobic; light shaded green: Van der Waals interaction.

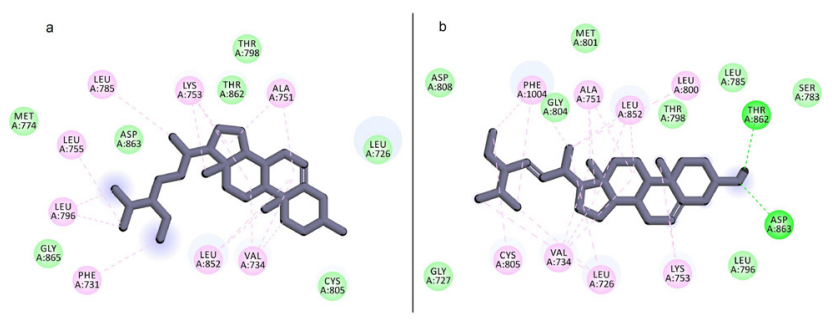

Figure 4: Interaction of (a) $\beta$-sitosterol and (b) stigmasterol with human epidermal growth factor receptor 2 (HER2). Green (with dashed line): hydrogen bond; pink (with dashed line): hydrophobic; light shaded green: Van der Waals interaction.

HER2 is implicated in the signaling of cancer cells facilitating the proliferation of malignant cells, ${ }^{47}$ and overexpression of EGFR is often observed in the aggressive triple negative breast cancer. ${ }^{48}$ Small molecule kinase inhibitors of HER2 alone or targeting both HER2 and EGFR have been implicated in breast cancer treatment. The phytosterols i.e. stigmasterol and $\beta$-sitosterol interacted efficiently with HER2 as shown in Figure 4. Stigmasterol had binding affinity of $-10.0 \mathrm{kcal} / \mathrm{mol}$ which is close to the binding affinity of reference ligand TAK-285 (-10.7 kcal) and it formed hydrogen bonds with Thr862A and Asp863A residue of kinase domain of receptor. Although paashaanolactone had lower binding affinity towards HER2 compared to stigmasterol and $\beta$-sitosterol, it formed four hydrogen bonds with Ser783A, Asn850A, Thr862A and Asp863A residue of kinase domain of HER2. Analysis of binding interaction of lapatinib which is a potent HER2 kinase inhibitor, suggests that amino acid residues in the range of 700 to 900 are essential for kinase activity of HER2. ${ }^{49}$ Since both stigmasterol and paashaanolactone interacted with the amino acids in this region with considerable binding affinity, the compounds may cause reduction of kinase activity of HER2. Afzelechin, $\beta$-sitosterol, paashaanolactone and stigmasterol had considerable binding affinity towards EGFR. The range of amino acids that interacted with the four compounds 


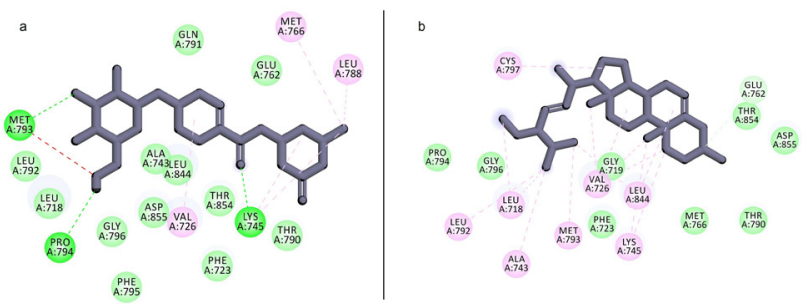

Figure 5: Interaction of (a) paashaanolactone and (b) stigmasterol with epidermal growth factor receptor 2 (EGFR). Green (with dashed line): hydrogen bond; pink (with dashed line): hydrophobic; light shaded green: Van der Waals interaction, cyan (with dashed line): carbon- hydrogen; red (with dashed line): unfavorable acceptor-acceptor interaction.

has similarity with that of EGFR inhibitors like erlotinib and AEE788. ${ }^{50}$ Therefore, these compounds may inhibit kinase activity of EGFR. Stigmasterol had greater affinity of $-8.8 \mathrm{kcal} / \mathrm{mol}$ towards EGFR than the corresponding native ligand AEE788 and interacted with Glu762A residue through formation of hydrogen bond. Paashaanolactone formed three hydrogen bonds with Lys745A, Met793A and Pro794A residue in EGFR kinase domain. Binding interactions of stigmasterol and paashaanolactone are illustrated in Figure 5.

Since these four compounds i.e. stigmasterol, $\beta$-sitosterol, paashaanolactone and afzelechin had considerable affinity towards the targets, they may be considered as credible leads for potential multitargeted therapy for breast cancer. Therefore, further structural modifications along with biological assays can be performed in search of new drugs.

\section{In silico ADME/T prediction}

Physicochemical properties that are associated with the pharmacokinetic or the ADME/T properties of the compounds with considerable binding affinities with breast cancer targets found in molecular docking are presented in Table 4. Lipinski's rule of five states that molecular properties of candidate compounds are required to be within certain ranges for better pharmacokinetics when used through oral route. The conditions of this rule for compounds are molecular weight $<500$, octanol-water partition ratio $(\log \mathrm{P})<5$, total number of hydrogen bond donor $\leq 5$, total number of hydrogen bond acceptor $\leq 10$, molar refractivity between $40-130 .^{51}$ High molecular weight compounds are less likely to cross membrane bilayer. The compounds whose lipophilicity values are less than 5 , are more than $90 \%$ likely to have good oral bioavailability. ${ }^{52}$ Molar refractivity is related to molecular weight and has influence on diffusion coefficient. ${ }^{53}$ High number of hydrogen bond donors and acceptors increases the interaction of the compound with hydrogen bonding solvents and thereby decreasing permeation through membrane bilayer. ${ }^{52}$ Afzelechin and paashaanolactone fulfilled all the aspects of Lipinski's rule of five. Therefore, these compounds are predicted to have good pharmacokinetic properties related to oral bioavailability. However, the phytosterols $\beta$-sitosterol and stigmasterol had one violation as these two compounds had higher lipophilicity value compared to the optimal range. As a result, these two phytosterols are supposed to bind with cell membrane strongly and have decreased bioavailability. To reduce the lipophilicity of these compounds, further structural modifications along with biopharmaceutical studies are required.

Pharmacokinetic and toxicological properties of the potent four compounds i.e. afzelechin, $\beta$-sitosterol, paashaanolactone and stigmasterol were predicted by in silico approach. Human intestinal absorption and human intestinal colon carcinoma cell (caco2) permeation values can give idea about intestinal absorption of a compound. ${ }^{54}$ Human intestinal absorption was found to be high for all compounds except paashaanolactone which also had low caco-2 permeability. Caco-2 permeability was low for afzelechin although its human intestinal absorption value was high. $\beta$-sitosterol and stigmasterol were found to be blood brain barrier permeant while afzelechin and paashaanolactone were not. CYP450 enzymes are involved in metabolism of drugs. None of the four compounds inhibited CYP2C19, CYP2C9, CYP2D6 and CYP3A4. Afzelechin was identified as substrate for CYP1A2 whereas $\beta$-sitosterol, paashaanolactone and stigmasterol were identified as substrates for CYP3A4. $\beta$-sitosterol and stigmasterol were shown to be substrate for P-glycoprotein which is a transmembrane protein and is associated with efflux of xenobiotics from cells. Therefore, $\beta$-sitosterol and stigmasterol may be extruded out of the cell by P-glycoprotein. The compounds also had no inhibitory effect on P-glycoprotein. All the compounds were found to be non-carcinogenic.

\section{CONCLUSION}

Fifteen compounds from Bergenia ciliata were screened for activity against breast cancer by molecular docking against ER- $\alpha$, PR, HER2 and EGFR. Among them stigmasterol, $\beta$-sitosterol, paashaanolactone and afzelechin showed efficient binding with the targets eliciting high affinity. These active compounds were selected for ADME/T prediction by in silico approach. Molecular docking investigation and calculation of 
Table 4: Physicochemical, ADME and toxicological properties of compounds from Bergenia ciliata.

\begin{tabular}{|c|c|c|c|c|}
\hline Physicochemical and ADMET properties & Afzelechin & $\beta$-sitosterol & Paashaanolactone & Stigmasterol \\
\hline Molecular weight & 274.27 & 414.71 & 412.39 & 412.69 \\
\hline Hydrogen bond acceptor & 5 & 1 & 10 & 1 \\
\hline Hydrogen bond donor & 4 & 1 & 4 & 1 \\
\hline Molar refractivity & 72.31 & 133.23 & 95.07 & 132.75 \\
\hline $\log P$ & 0.79 & 6.73 & -0.62 & 6.62 \\
\hline Human intestinal absorption & +0.991 & +0.993 & -0.539 & +0.991 \\
\hline Caco-2 permeability & -0.808 & +0.539 & -0.798 & +0.546 \\
\hline Blood brain barrier & -0.278 & +0.925 & -0.625 & +0.925 \\
\hline CYP1A2 inhibition & No & No & No & No \\
\hline CYP2C19 inhibition & No & No & No & No \\
\hline CYP2C9 inhibition & No & No & No & No \\
\hline CYP2C9 substrate & No & No & No & No \\
\hline CYP2D6 inhibition & No & No & No & No \\
\hline CYP2D6 substrate & Yes & No & No & No \\
\hline CYP3A4 inhibition & No & No & No & No \\
\hline CYP3A4 substrate & No & Yes & Yes & Yes \\
\hline P-glycoprotein inhibitor & No & No & No & No \\
\hline P-glycoprotein substrate & No & Yes & No & Yes \\
\hline Carcinogenecity & No & No & No & No \\
\hline
\end{tabular}

$\mathrm{ADME} / \mathrm{T}$ attributes revealed that these compounds may be considered as lead for further structural modifications, in vitro and in vivo studies in the quest for developing new multi-targeted drugs for treating breast cancer.

\section{ACKNOWLEDGEMENT}

The authors express gratitude towards Department of Clinical Pharmacy and Pharmacology, Faculty of Pharmacy, University of Dhaka for providing required research facility.

\section{CONFLICT OF INTEREST}

The authors declare no conflict of interests.

\section{ABBREVIATIONS}

ER- $\alpha$ : Estrogen receptor- $\alpha$ : PR: Progesterone receptor; HER2/ ERBB2: Human epidermal growth factor receptor 2/ Erb-B2 receptor tyrosine kinase 2; EGFR:
Epidermal growth factor receptor; TAK-285: N-[2[4-[3-chloro-4-[3-(trifluoromethyl)phenoxy]anilino] pyrrolo[3,2-d]pyrimidin-5-yl]ethyl]-3-hydroxy-3-methylbutanamide; AEE788: 6-[4-[(4-ethylpiperazin-1-yl) methyl]phenyl]- $N$-[(1R)-1-phenylethyl]-7 H-pyrrolo[2,3d]pyrimidin-4-amine; ADME/T: Absorption, distribution, metabolism, excretion and toxicity; CYP1A2: Cytochrome P450 family 1 subfamily A member 2; CYP2C19:Cytochrome P450 family 2 subfamily C member 19; CYP2C9: Cytochrome P450 family 2 subfamily C member 9; CYP2D6: Cytochrome P450 family 2 subfamily D member 6 CYP3A4: Cytochrome P450 family 3 subfamily A member 4 .

\section{REFERENCES}

1. Sun YS, Zhao Z, Yang ZN, Xu F, Lu HJ, Zhu ZY, et al. Risk factors and preventions of breast cancer. Int J Biol Sci. 2017;13(11):1387-97. doi: 10.7150/ijbs.21635, PMID 29209143.

2. Tao Z, Shi A, Lu C, Song T, Zhang Z, Zhao J. Breast Cancer: epidemiology and etiology. Cell Biochem Biophys. 2015;72(2):333-8. doi: 10.1007/s12013014-0459-6, PMID 25543329. 
3. Heer E, Harper A, Escandor N, Sung H, McCormack V, Fidler-Benaoudia MM. Global burden and trends in premenopausal and postmenopausal breast cancer: a population-based study. Lancet Glob Health. 2020;8(8):e1027-37. doi: 10.1016/S2214-109X(20)30215-1, PMID 32710860.

4. Huang J, Chan PS, Lok V, Chen X, Ding H, Jin Y, et al. Global incidence and mortality of breast cancer: a trend analysis. Aging (Albany, NY). 2021;13(4):5748-803. doi: 10.18632/aging.202502, PMID 33592581.

5. Youlden DR, Cramb SM, Dunn NAM, Muller JM, Pyke CM, Baade PD. The descriptive epidemiology of female breast cancer: an international comparison of screening, incidence, survival and mortality. Cancer Epidemiol. 2012;36(3):237-48. doi: 10.1016/j.canep.2012.02.007, PMID 22459198.

6. Chen W, Hoffmann AD, Liu H, Liu X. Organotropism: new insights into molecular mechanisms of breast cancer metastasis. npj Precis Oncol. 2018;2(1):4. doi: 10.1038/s41698-018-0047-0, PMID 29872722.

7. Riggio $\mathrm{Al}$, Varley $\mathrm{KE}$, Welm $\mathrm{AL}$. The lingering mysteries of metastatic recurrence in breast cancer. Br J Cancer. 2021;124(1):13-26. doi: 10.1038/ s41416-020-01161-4, PMID 33239679.

8. Thorat MA, Balasubramanian R. Breast cancer prevention in high-risk women. Best Pract Res Clin Obstet Gynaecol. 2020;65:18-31. doi: 10.1016/j. bpobgyn.2019.11.006, PMID 31862315.

9. Daly AA, Rolph R, Cutress RI, Copson ER. A review of modifiable risk factors in young women for the prevention of breast cancer. Breast Cancer (Dove Med Press). 2021;13:241-57. doi: 10.2147/BCTT.S268401, PMID 33883932.

10. Gao JJ, Swain SM. Luminal A breast cancer and molecular assays: A review. Oncologist. 2018;23(5):556-65. doi: 10.1634/theoncologist.2017-0535, PMID 29472313.

11. Yanagawa M, Ikemot $\mathrm{K}$, Kawauchi S, Furuya T, Yamamoto S, Oka M, et al. Luminal A and luminal B (HER2 negative) subtypes of breast cancer consist of a mixture of tumors with different genotype. BMC Res Notes. 2012;5(1):376. doi: 10.1186/1756-0500-5-376, PMID 22830453.

12. Ismail-Khan R, Bui MM. A review of triple-negative breast cancer. Cancer Control. 2010;17(3):173-6. doi: 10.1177/107327481001700305, PMID 20664514.

13. Waks AG, Winer EP. Breast cancer treatment: a review. JAMA. 2019;321(3):288-300. doi: 10.1001/jama.2018.19323, PMID 30667505.

14. Rossi L, McCartney A, De Santo I, Risi E, Moretti E, Malorni L, et al. The optimal duration of adjuvant endocrine therapy in early luminal breast cancer: A concise review. Cancer Treat Rev. 2019;74:29-34. doi: 10.1016/j. ctrv.2019.01.007, PMID 30708267.

15. Kang $\mathrm{H}$, Xiao X, Huang $\mathrm{C}$, Yuan $\mathrm{Y}$, Tang D, Dai X, et al. Potent aromatase inhibitors and molecular mechanism of inhibitory action. Eur J Med Chem. 2018;143:426-37. doi: 10.1016/j.ejmech.2017.11.057, PMID 29202405.

16. Brandão $M$, Pondé NF, Poggio F, Kotecki N, Salis M, Lambertini M, et al. Combination therapies for the treatment of HER2-positive breast cancer: current and future prospects. Expert Rev Anticancer Ther. 2018;18(7):629-49. doi: 10.1080/14737140.2018.1477596, PMID 29781317.

17. Collignon J, Lousberg L, Schroeder H, Jerusalem G. Triple-negative breast cancer: treatment challenges and solutions. Breast Cancer (Dove Med Press). 2016;8:93-107. doi: 10.2147/BCTT.S69488, PMID 27284266.

18. Tran B, Bedard PL. Luminal-B breast cancer and novel therapeutic targets. Breast Cancer Res. 2011;13(6):221. doi: 10.1186/bcr2904, PMID 22217398.

19. Mantaj J, Rahman SMA, Bokshi B, Hasan CM, Jackson PJM, Parsons RB, et al. Crispene $\mathrm{E}$, a cis-clerodane diterpene inhibits STAT3 dimerization in breast cancer cells. Org Biomol Chem. 2015;13(13):3882-6. doi: 10.1039/ c5ob00052a, PMID 25721973.

20. Tiwari V, Meena B, Nair NK, Rana TS. Molecular analyses of genetic variability in the populations of Bergenia ciliata in Indian Himalayan Region (IHR). Physiol Mol Biol Plants. 2020;26(5):975-84. doi: 10.1007/s12298-02000797-z, PMID 32377047.

21. Uddin G, Rauf A, Arfan M, Ali M, Qaisar M, Saadiq M, et al. Preliminary phytochemical screening and antioxidant activity of Bergenia ciliata. Middle East J Sci Res. 2012;11(8):1140-2.

22. Ahmad M, Butt MA, Zhang G, Sultana S, Tariq A, Zafar M. Bergenia ciliata: a comprehensive review of its traditional uses, phytochemistry, pharmacology and safety. Biomed Pharmacother. 2018;97:708-21. doi: 10.1016/j. biopha.2017.10.141, PMID 29102914.

23. Khan MY, Kumar V. Phytopharmacological and chemical profile of Bergenia ciliata. Int J Phytopharmacol 2016. Vol. 6(5). p. 90-8.
24. Koul B, Kumar A, Yadav D, Jin JO. Bergenia genus: traditional uses, phytochemistry and pharmacology. Molecules. 2020;25(23):5555. doi: 10.3390/molecules25235555, PMID 33256153.

25. Byahatti VV, Pai KV, D'Souza MG. Effect of phenolic compounds from Bergenia ciliata (Haw.) Sternb. leaves on experimental kidney stones. Anc Sci Life. 2010;30(1):14-7. PMID 22557418.

26. Phull A-R, Abbas Q, Ali A, Raza H, Kim SJ, Zia M, et al. Antioxidant, cytotoxic and antimicrobial activities of green synthesized silver nanoparticles from crude extract of Bergenia ciliata. Future Journal of Pharmaceutical Sciences. 2016;2(1):31-6. doi: 10.1016/j.jps.2016.03.001.

27. Bhandari MR, Jong-Anurakkun N, Hong G, Kawabata J. a-glucosidase and a-amylase inhibitory activities of Nepalese medicinal herb Pakhanbhed (Bergenia ciliata, Haw.). Food Chem. 2008;106(1):247-52. doi: 10.1016/j. foodchem.2007.05.077.

28. Sinha S, Murugesan T, Pal M, Saha BP. Evaluation of anti-tussive activity of Bergenia ciliata Sternb. rhizome extract in mice. Phytomedicine. 2001;8(4):298-301. doi: 10.1078/0944-7113-00039, PMID 11515720.

29. Zia G, Sadia H, Nazir S, Ejaz K, Ali S, Ihsan-Ul-Haq, Iqbal T, Khan MAR, Raza A, Andleeb S. In vitro Studies on Cytotoxic, DNA protecting, antibiofilm and antibacterial effects of biogenic silver nanoparticles prepared with Bergenia ciliata rhizome extract. Curr Pharm Biotechnol. 2018;19(1):68-78. doi: 10.2174/1389201019666180417160049, PMID 29667550.

30. Pokhrel P, Banerjee J, Dahal P, Khanal H, Gupta AK, Kumar Dey B, et al. Phytochemical screening and biological evaluation of different parts of plant Bergenia ciliata. J Pharmacogn Phytochem. 2014;3(4):220-4.

31. Kumar RA, Rajkumar V, Guha G, Kumar RA. Anti-neoplastic activities of Bergenia ciliata rhizome. J Pharm Res. 2011;4(2):443-5.

32. Shiau AK, Barstad D, Loria PM, Cheng L, Kushner PJ, Agard DA, Greene GL. The structural basis of estrogen receptor/coactivator recognition and the antagonism of this interaction by tamoxifen. Cell. 1998;95(7):927-37. doi: 10.1016/s0092-8674(00)81717-1, PMID 9875847.

33. Petit-Topin I, Fay M, Resche-Rigon M, Ulmann A, Gainer E, Rafestin-Oblin ME, Fagart J. Molecular determinants of the recognition of ulipristal acetate by oxo-steroid receptors. J Steroid Biochem Mol Biol. 2014;144(B):427-35. doi: 10.1016/j.jsbmb.2014.08.008, PMID 25204619.

34. Ishikawa $\mathrm{T}$, Seto $\mathrm{M}$, Banno $\mathrm{H}$, Kawakita $\mathrm{Y}$, Oorui M, Taniguchi $\mathrm{T}$, et al. Design and synthesis of novel human epidermal growth factor receptor 2 (HER2)/epidermal growth factor receptor (EGFR) dual inhibitors bearing a pyrrolo[3,2-d]pyrimidine scaffold. J Med Chem. 2011;54(23):8030-50. doi: 10.1021/jm2008634, PMID 22003817.

35. Yun CH, Boggon TJ, Li Y, Woo MS, Greulich H, Meyerson M, et al. Structures of lung cancer-derived EGFR mutants and inhibitor complexes: mechanism of activation and insights into differential inhibitor sensitivity. Cancer Cell. 2007;11(3):217-27. doi: 10.1016/j.ccr.2006.12.017, PMID 17349580.

36. O'Boyle NM, Banck M, James CA, Morley C, Vandermeersch T, Hutchison GR. Open Babel: an open chemical toolbox. J Cheminform. 2011;3(10):33. doi: 10.1186/1758-2946-3-33, PMID 21982300.

37. Trott O, Olson AJ. AutoDock Vina: improving the speed and accuracy of docking with a new scoring function, efficient optimization, and multithreading. J Comput Chem. 2010;31(2):455-61. doi: 10.1002/jcc.21334, PMID 19499576.

38. Daina A, Michielin O, Zoete V. SwissADME: A free web tool to evaluate pharmacokinetics, drug-likeness and medicinal chemistry friendliness of small molecules. Sci Rep. 2017;7:42717. doi: 10.1038/srep42717. PMID 28256516.

39. Ali S, Coombes RC. Estrogen receptor alpha in human breast cancer: Occurrence and significance. J Mammary Gland Biol Neoplasia. 2000;5(3):271-81. doi: 10.1023/a:1009594727358, PMID 14973389.

40. Shagufta Al, Ahmad I. Tamoxifen a pioneering drug: An update on the therapeutic potential of tamoxifen derivatives. Eur J Med Chem. 2018;143:515-31. doi: 10.1016/j.ejmech.2017.11.056, PMID 29207335.

41. Majumder R, Parida P, Paul S, Basak P. In vitro and in silico study of Aloe vera leaf extract against human breast cancer. Nat Prod Res. 2020;34(16):2363-6. doi: 10.1080/14786419.2018.1534848, PMID 30600703.

42. Muchtaridi M, Syahidah HN, Subarnas A, Yusuf M, Bryant SD, Langer T. Molecular docking and 3D-pharmacophore modeling to study the interactions of chalcone derivatives with estrogen receptor alpha. Pharmaceuticals. 2017;10(4):81. doi: 10.3390/ph10040081. 
43. Hung $\mathrm{H}$. Inhibition of estrogen receptor alpha expression and function in MCF-7 cells by kaempferol. J Cell Physiol. 2004;198(2):197-208. doi: 10.1002/jcp.10398, PMID 14603522.

44. Mohammed H, Russell IA, Stark R, Rueda OM, Hickey TE, Tarulli GA et al. Progesterone receptor modulates ERa action in breast cancer. Nature. 2015;523(7560):313-7. doi: 10.1038/nature14583, PMID 26153859.

45. Klijn JGM, Setyono-Han B, Foekens JA. Progesterone antagonists and progesterone receptor modulators in the treatment of breast cancer. Steroids. 2000;65(10-11):825-30. doi: 10.1016/s0039-128x(00)00195-1, PMID 11108894.

46. Dean M, Austin J, Jinhong R, Johnson ME, Lantvit DD, Burdette JE. The flavonoid apigenin is a progesterone receptor modulator with in vivo activity in the uterus. Horm Cancer. 2018;9(4):265-77. doi: 10.1007/s12672-0180333-x, PMID 29736565.

47. Yarden Y. Biology of HER2 and its importance in breast cancer. Oncology. 2001;61(2);Suppl 2:1-13. doi: 10.1159/000055396, PMID 11694782.

48. Maennling AE, Tur MK, Niebert M, Klockenbring T, Zeppernick F, Gattenlöhner $\mathrm{S}$, et al. Molecular targeting therapy against EGFR family in breast cancer: progress and future potentials. Cancers. 2019;11(12):1826. doi: 10.3390/ cancers11121826, PMID 31756933.

49. Chandrika BB, Steephan M, Kumar TRS, Sabu A, Haridas M. Hesperetin and naringenin sensitize HER2 positive cancer cells to death by serving as
HER2 tyrosine kinase inhibitors. Life Sci. 2016;160:47-56. doi: 10.1016/j. Ifs.2016.07.007, PMID 27449398.

50. Sharma VK, Nandekar PP, Sangamwar A, Pérez-Sánchez H, Agarwal SM. Structure guided design and binding analysis of EGFR inhibiting analogues of erlotinib and AEE788 using ensemble docking, molecular dynamics and MMGBSA. RSC Adv. 2016;6(70):65725-35. doi: 10.1039/C6RA08517B.

51. Spriha SE, Rahman FI, Rahman SMA. Synthesis, in vivo and in silico analgesic and anti-inflammatory studies of $\alpha$-D-ribofuranose derivatives. Saudi Pharm J. 2021. doi: 10.1016/j.jsps.2021.07.017.

52. Pollastri MP. Overview on the rule of five. Curr Protoc Pharmacol. 2010; Chapter(9):9.12.1-9.12.8. doi: 10.1002/0471141755.ph0912s49, PMID 22294375.

53. Kuentz MT, Arnold Y. Influence of molecular properties on oral bioavailability of lipophilic drugs - mapping of bulkiness and different measures of polarity. Pharm Dev Technol. 2009;14(3):312-20. doi: 10.1080/10837450802626296, PMID 19235630.

54. Ta GH, Jhang CS, Weng CF, Leong MK. Development of a hierarchical support vector regression-based in silico model for caco-2 permeability. Pharmaceutics. 2021;13(2):174. doi: 10.3390/pharmaceutics13020174, PMID 33525340.

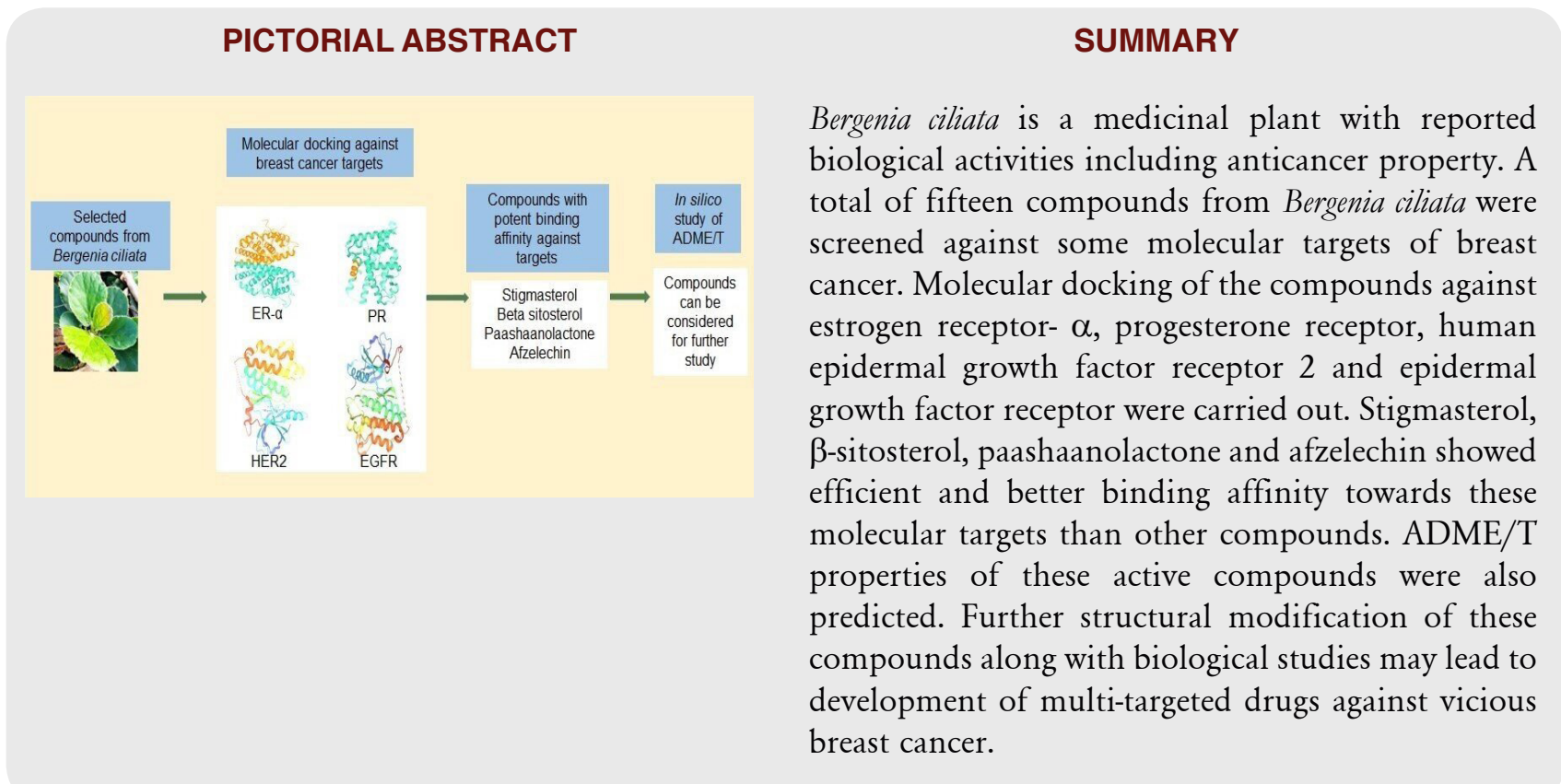




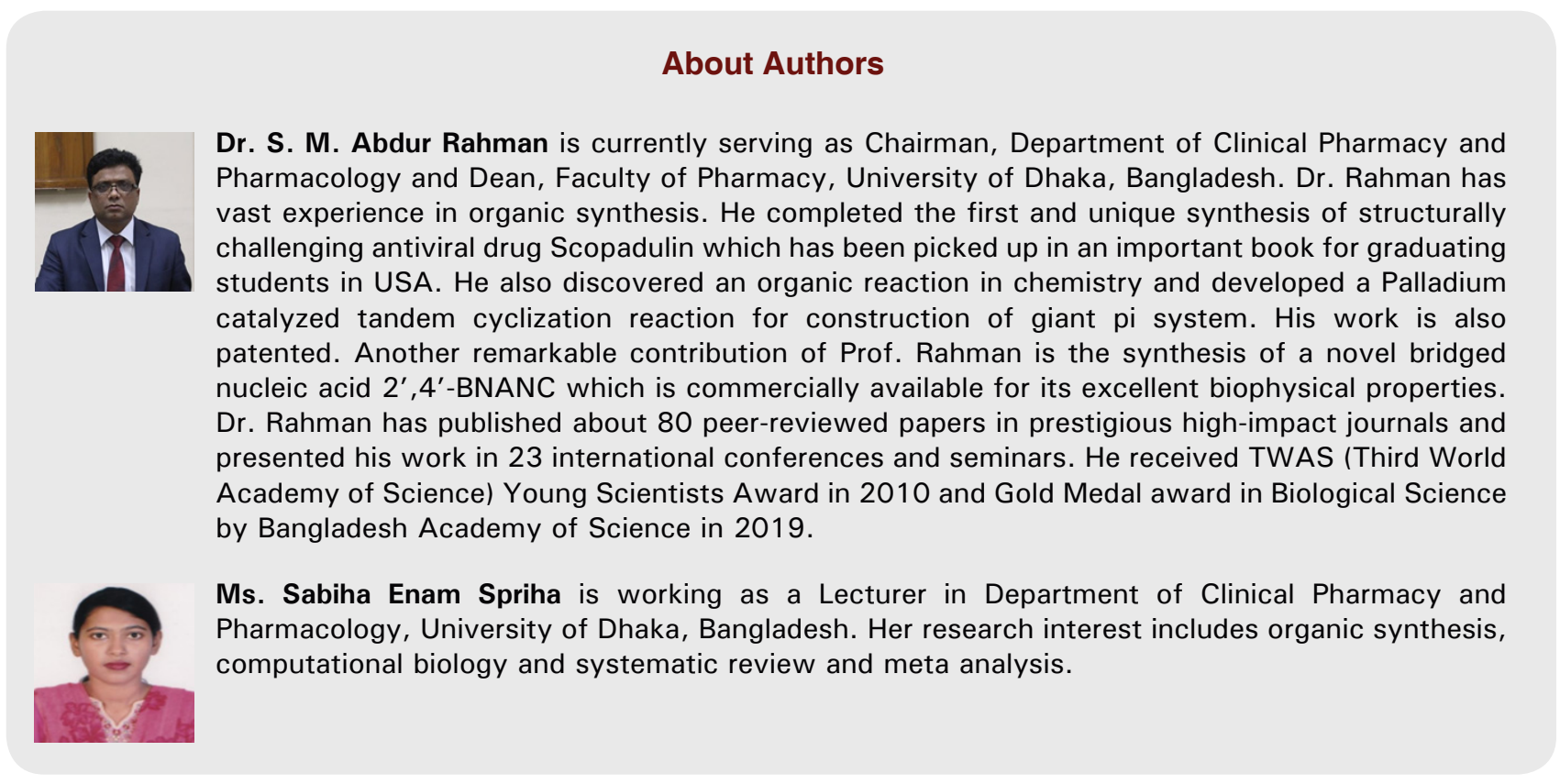

Cite this article: Spriha SE, Rahman SMA. In silico Evaluation of Selected Compounds from Bergenia ciliata (Haw.) Sternb against Molecular Targets of Breast Cancer. Indian J of Pharmaceutical Education and Research. 2022;56(1s):s105-s114. 